\title{
OPTIMASI DAN MONITORING PERINGKAT GREEN BUILDING PADA GEDUNG TERBANGUN DI GEDUNG SAMPOERNA STRATEGIC SQUARE JAKARTA
}

\author{
Firma Purbantoro ${ }^{1}$, Marsul Siregar ${ }^{2}$ \\ ${ }^{1}$ Mahasiswa Magister Teknik Elektro, Universitas Katolik Indonesia Atmajaya Jakarta \\ Email: firma.purbantoro@sampoernaland.com \\ ${ }^{2}$ Dosen Fakultas Teknik, Universitas Katolik Indonesia Atmajaya Jakarta \\ Email: marsul.siregar@atmajaya.ac.id
}

\begin{abstract}
ABSTRAK
Konsep Bangunan hijau / Green Building yang sedang menjadi tren secara global apabila diterapkan maka bukan saja akan memperkuat brand image dari bangunan itu sendiri tetapi juga bisa menghemat biaya operasional pengelolaan gedung, Metode penelitian yang digunakan adalah kualitatif dan kuantitatif. Metode kualitatif dilakukan melalui wawancara dengan pengelola gedung dan kamimteam konsultan perencana dari Fakultas Teknik Universitas Atmajaya, studi kepustakaan, observasi/pengamatan, dan dokumentasi.. dalam studi kasus gedung sampoerna strategic square setelah melakukan pekerjaan retrofit sistem Ventilation Air Condition (VAC) dengan mengganti chiller, Recycle air buangan, penggantian lampu konvensional dengan lampu Hemat Energi dan juga sosialisasi kepada seluruh karyawan dan penyewa, maka didapatkan penghematan dari pembayaran tagihan listrik saja sebesar Rp 477.932.856,43 / bulan (18\%) dan secara kasar akan kembali modal selama 3,77 Tahun.
\end{abstract}

Kata Kunci: Green Building, Penghematan Energi, Retrofit, Return on Investment

\section{PENDAhULUAN}

Konsep bangunan Hijau / Green Building saat ini sudah menjadi tren didunia, ada beberapa lembaga yang mengeluarkan sertifikasi diantaranya USGBC LEED [1][2], Singapore BCAGreen Mark[3] dan GBCI[4], Penelitian ini mengambil rating tool sertifikasi dari green building council Indonesia untuk sertifikasi gedung terbangun. Lembaga Konsil Bangunan Hijau Indonesia atau Green Building Council Indonesia (GBC Indonesia) adalah lembaga mandiri (non government) yang berkomitmen penuh terhadap pendidikan masyarakat dalam mengaplikasikan praktik-praktik terbaik lingkungan dan memfasilitasi transformasi industri bangunan global yang berkelanjutan[3]. GBC Indonesia saat ini sudah mengeluarkan 5 jenis Greenship, yaitu: Greenship New Building, Greenship existing building, greenship interior space, Greenship homes dan greenship neighborhoods.

Greenship untuk Gedung Terbangun digunakan untuk bangunan gedung yang telah lama beroperasi minimal satu tahun setelah gedung selesai dibangun. Implementasi green building pada gedung terbangun banyak terkait dengan manajemen operasional dan pemeliharaan gedung. Penelitian ini mengambil studi kasus Greenship untuk gedung terbangun yaitu Gedung Sampoerna Strategic Square yang adalah gedung perkantoran yang memiliki Dua Tower yang masing-masing terdiri dari 32 lantai dan 3 lantai basement. Konsumsi listrik terdiri dari sistem Ventilating Air Conditioning 51\%, Sistem Penerangan 20\%, Sewage Treatment Plant 9\%, Lift $8 \%$, Pompa 7\%, Komputer dan lainnya 5\%

Greenship Rating Tools untuk gedung terbangun terbagi atas enam kategori yang terdiri dari : Tepat Guna Lahan - Appropriate Site Development (ASD), Efisiensi dan Konservasi Energi Energy Efficiency \& Conservation (EEC), Konservasi Air - Water Conservation (WAC), Sumber \& Siklus Material - Material Resources \& Cycle (MRC), Kualitas Udara \& 
Kenyamanan Udara Dalam Ruang - Indoor Air Health \& Comfort (IHC), Manajemen Lingkungan Bangunan - Building \& Enviroment Management (BEM). Penghargaan / award untuk gedung existing terdiri dari beberapa kriteria yang bisa dilihat di Table 1 .

Tabel 1. Penghargaan/award untuk bangunan existing/Gedung Terbangun VERSI 1.1

\begin{tabular}{|l|c|c|}
\hline \multicolumn{1}{|c|}{ Peringkat } & Persentase & Nilai Minimal \\
\hline Platinum & $73 \%$ & 86 \\
\hline Gold & $57 \%$ & 67 \\
\hline Silver & $46 \%$ & 54 \\
\hline Bronze Total & $35 \%$ & 41 \\
\hline \multicolumn{2}{|c|}{ Tor } & 117 \\
\hline
\end{tabular}

Sumber ; http://gbcindonesia.org/greenship/rating-tools.

Penelitian ini mengambil studi kasus gedung Sampoerna Strategic Square (SSS) yang pada tahun 2012 memperoleh peringkat Gold dan berencana untuk mendapatkan peringkat Platinum, perolehan point di tahun 2012 yaitu 72 point yang berarti hanya memperoleh peringkat Gold

Tabel 2. Penghargaan / Peringkat yang didapat gedung tahun 2012 [4]

\begin{tabular}{|l|c|c|}
\hline \multicolumn{1}{|c|}{ Kategori } & Point & Point Tersedia \\
\hline Appropriate Site Development & 2012 & \\
\hline Energy Efficiency \& Conservation & 8 & 16 \\
\hline Water Conservation & 17 & 36 \\
\hline Material Resources \& Cycle & 19 & 20 \\
\hline Indoor Air Health \& Comfort & 6 & 12 \\
\hline Building \& Environment Management & 14 & 20 \\
\hline & 8 & 13 \\
\hline & & 117 \\
\hline Perolehan nilai / Point & 72 & \\
\hline Perolehan Peringkat & GOLD & \\
\hline
\end{tabular}
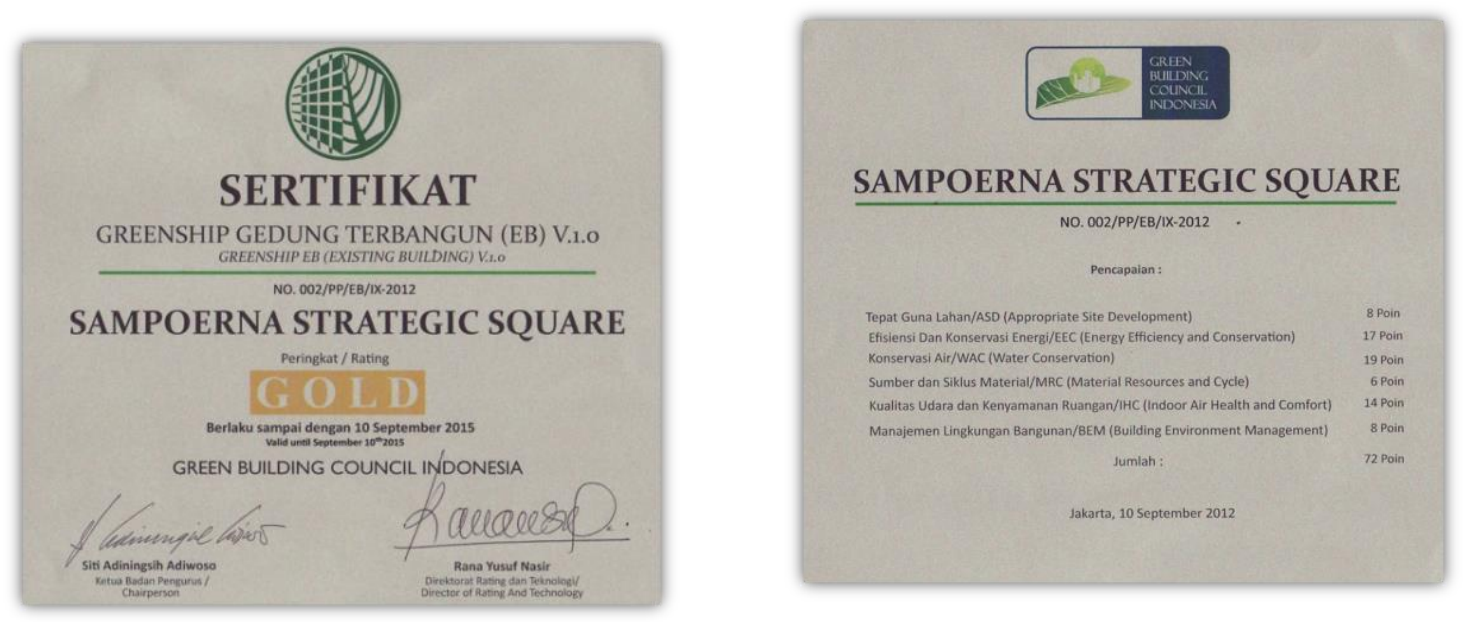

Gambar 1. Penghargaan dan nilai yang didapatkan pada tahun 2012 
Pembayaran Listrik PLN perbulan pada tahun 2014 sebelum dilakukan retrofit bisa dilihat di Table 3 dibawah ini.

Tabel 3. Neraca Listrik sebagai Baseline Konsumsi Energi Tahun 2014 sebesar 28,203,480

\begin{tabular}{|l|c|c|c|c|c|}
\hline \multirow{2}{*}{ Bulan } & \multirow{2}{*}{ Tahun } & \multicolumn{2}{c|}{ PLN } & \multirow{2}{*}{ TOTAL } & \multirow{2}{*}{ Rupiah } \\
\cline { 3 - 4 } & & LWBP & WBP & & \\
\hline Januari & 2014 & $1,892,760$ & 307,800 & $2,200,560$ & $2,796,413,194$ \\
\hline Februari & 2014 & $1,912,320$ & 294,480 & $2,206,800$ & $2,459,192,381$ \\
\hline Maret & 2014 & $2,059,440$ & 325,920 & $2,385,360$ & $2,458,753,699$ \\
\hline April & 2014 & $2,046,600$ & 289,320 & $2,335,920$ & $2,590,922,198$ \\
\hline Mei & 2014 & $2,040,120$ & 310,440 & $2,350,560$ & $2,661,675,274$ \\
\hline Juni & 2014 & $2,087,400$ & 306,240 & $2,393,640$ & $2,960,947,907$ \\
\hline Juli & 2014 & $1,902,480$ & 306,240 & $2,208,720$ & $3,007,494,036$ \\
\hline Agustus & 2014 & $2,113,680$ & 321,480 & $2,435,160$ & $2,732,377,851$ \\
\hline September & 2014 & $2,117,760$ & 315,000 & $2,432,760$ & $3,150,719,192$ \\
\hline Oktober & 2014 & $2,190,000$ & 327,600 & $2,517,600$ & $3,065,388,481$ \\
\hline November & 2014 & $2,056,080$ & 320,520 & $2,376,600$ & $3,140,022,359$ \\
\hline Desember & 2014 & $2,059,440$ & 300,360 & $2,359,800$ & $2,966,604,401$ \\
\hline TOTAL & & $24,478,080$ & $3,725,400$ & $28,203,480$ & $33,990,510,973$ \\
\hline Rata-rata & & $2,039,840$ & 310,450 & $2,350,290$ & $2,832,542,581$ \\
\hline
\end{tabular}

kWh/Tahun dan Rata-rata Pembayaran Listrik Rp 2,832,542,581/bulan

\section{METODE PENELITIAN}

Tempat dan waktu penelitian dilaksanakan dari bulan Januari 2016 sampai Desember 2018 dengan mengambil data gedung saat memperoleh peringkat silver kemudian melakukan upayaupaya perbaikan (retrofit) sistem Ventilation Air Conditioning, Water Recycle dan Perbaikan kualitas udara dalam ruangan sehingga pada tahun 2017 dapat meningkatkan peringkat penghargaan menjadi platinum dan monitoring laporan utility untuk menentukan waktu kembalinya modal/Return on Invesment (ROI) yang telah dikeluarkan dalam upaya untuk perbaikan peringkat Greenship.

Metode penelitian yang digunakan adalah kualitatif dan kuantitatif. Metode kualitatif dilakukan melalui wawancara dengan pengelola gedung dan kamimteam konsultan perencana dari Fakultas Teknik Universitas Atmajaya, studi kepustakaan, observasi/pengamatan, dan dokumentasi. Sedangkan metode kuantitatif bertujuan untuk mencari hubungan atau menjelaskan sebab-sebab perubahan yang berdasarkan fakta-fakta yang terukur berdasarkan data yang bersifat angka, dapat diamati dan diukur. Data yang dipakai dalam penelitian ini adalah data primer dan data sekunder. Data primer adalah data perencanaan gedung dari pihak konsultan perencana bangunan, data perangkat penilaian greenship dari GBC 
Indonesia, dan data dari penelitian langsung yang didapat peneliti melalui survei, wawancara, dan pengukuran. Data sekunder adalah data yang dikumpulkan oleh pihak lain dan telah didokumentasikan sehingga dapat digunakan oleh pihak lain (peneliti).

\section{PERBAIKAN / RETROFIT}

3.1 Perbaikan Fisik dengan melakukan retrofit, perbaikan dilakukan untuk memperbaiki Intensitas Konsumsi Energi [5], indek konsumsi air [5] dan system sirkulasi udara

Tabel 4. Perbaikan Secara Fisik dengan Melakukan Retrofit

\begin{tabular}{|l|l|l|}
\hline \multicolumn{1}{|c|}{ Item Retrofit / Perbaikan } & \multicolumn{1}{c|}{ Kategori } & \multicolumn{1}{c|}{ Biaya (Rp) } \\
\hline $\begin{array}{l}\text { Penggantian 4 Unit Chiller (1000 TR) Type } \\
\text { Screw Compressor dengan type yang lebih } \\
\text { hemat energy }\end{array}$ & $\begin{array}{l}\text { Energy Efficiency \& } \\
\text { Conservation }\end{array}$ & 16.577 .000 .000 \\
\hline $\begin{array}{l}\text { Perbaikan Sistem Recycle Air kotor untuk } \\
\text { dimanfaatkan sebagai air pendingin cooling } \\
\text { tower }\end{array}$ & Water Conservation & 1.800 .000 .000 \\
\hline Penggantian Lampu TLD dengan LED[6] & $\begin{array}{l}\text { Energy Efficiency \& } \\
\text { Conservation }\end{array}$ & 3.250 .000 .000 \\
\hline Total Biaya & & 21.627 .000 .000 \\
\hline
\end{tabular}

Standar Intensitas Konsumsi Energi untuk gedung perkantoran bisa dilihat seperti dimuat dalam Table 5 dibawah ini.

Tabel 5. Standar Intensitas Konsumsi Energi untuk Gedung Perkantoran

\begin{tabular}{|l|c|c|}
\hline \multicolumn{1}{|c|}{ Sumber } & $\begin{array}{c}\text { IKE } \\
\left(\mathbf{k W H} / \mathbf{m}^{2} / \text { tahun }\right)\end{array}$ & $\begin{array}{c}\text { Tahun Pengeluaran } \\
\text { standar }\end{array}$ \\
\hline ASEAN - USAID & 240 & 1987 \\
\hline $\begin{array}{l}\text { ESDM \& JICA Electric Power } \\
\text { Development Co Ltd }\end{array}$ & 198,2 & 2008 \\
\hline GBCIndonesia & 250 & 2010 \\
\hline $\begin{array}{l}\text { Pergub DKI Jakarta No.38 tahun 2012 } \\
\text { Tentang Bangunan Gedung Hijau } \\
\text { 6. }\end{array}$ & $210-285$ & 2012 \\
\hline
\end{tabular}


3.2 Perbaikan non Fisik dengan melakukan sosialisasi penghematan energi ke seluruh karyawan dan penghuni gedung
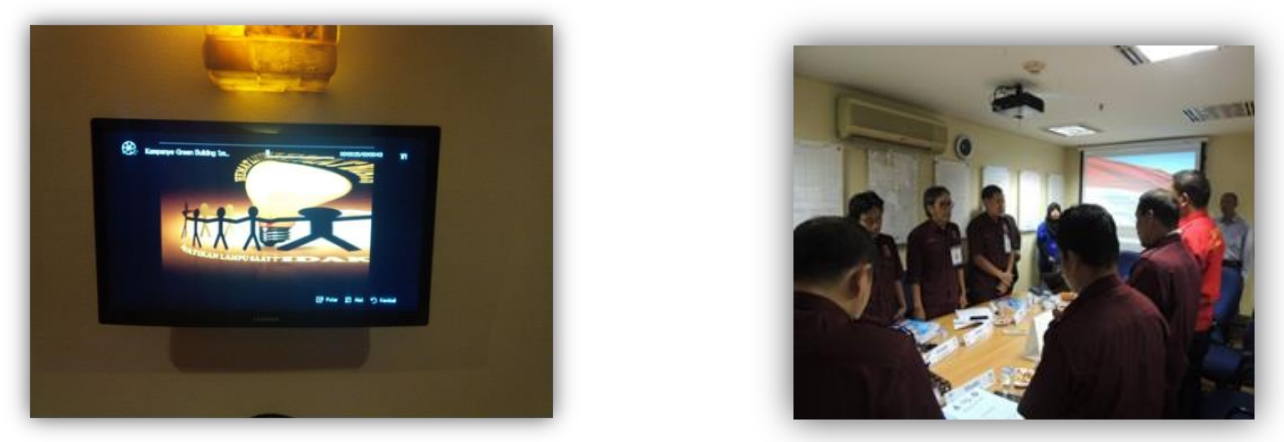

Gambar 2. Sosialisasi dan Training

\section{HASIL DAN PEMBAHASAN}

\subsection{Hasil Retrofit}

Hasil Retrofit difokuskan pembahasan Coeficient of Performances Chiller dan

Penghematan penggunaan air.

\subsubsection{Penggantian Chiller}

Hasil Retrofit dapat diketahui performancenya dari effisiensi chiller yang dapat dilihat di gambar 3 dibawah ini, dari gambar diketahui COP chiller lama 3,8 dan chiller baru 5,0 atau ada perbaikan sekitar $25 \%$
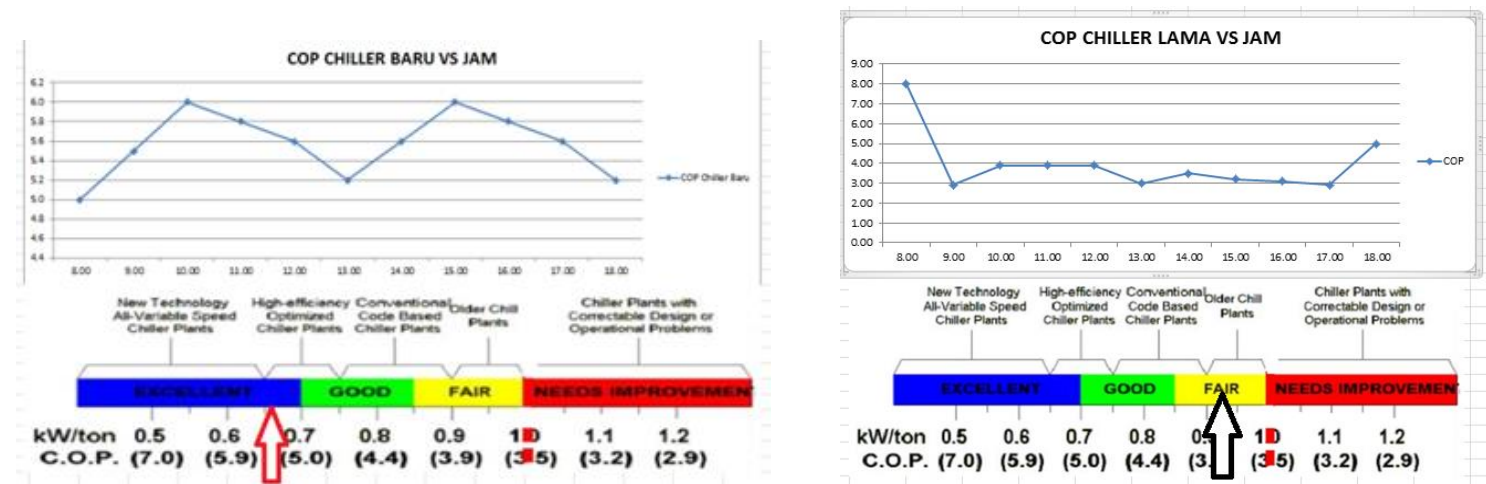

Gambar 3. Perbandingan Nilai Coefficient Of Performance (COP) Chiller Lama

Sedangkan Perbandingan Effisiensi Chiller lama dan baru dapat dilihat di tabel 6 dibawah, dari tabel diketahui pada Chiller lama untuk mendapatkan pendinginan sebesar 1 Ton of Refrigeration (TR) dibutuhkan energi sebesar 1,63 kW, sedangkan di Chiller baru untuk mendapatkan pendinginan sebesar 1 Ton of Refrigeration (TR) dibutuhkan energi sebesar 0,89 $\mathrm{kW}$, artinya dengan chiller baru kita mendapatkan penghematan sekitar 50\% dibandingkan dengan chiller lama. 
Tabel 6. Perbandingan Effisiensi Chiller lama dan baru

\begin{tabular}{|l|c|c|}
\hline \multirow{2}{*}{ Chiller Plant } & \multicolumn{2}{|c|}{ Perbandingan Effisiensi } \\
\cline { 2 - 3 } & $\begin{array}{c}\text { Sebelum } \\
\text { (kW/TR) }\end{array}$ & $\begin{array}{c}\text { Sesudah } \\
\text { (kW/TR) }\end{array}$ \\
\hline Chiller (A) & 0,95 & 0,53 \\
\hline Pompa CHWP (B) & 0,3 & 0,15 \\
\hline Pompa CWP (C) & 0,3 & 0,15 \\
\hline Cooling Tower (D) & 0,08 & 0,04 \\
\hline Sistem Effisiensi & 1,63 & 0,89 \\
\hline (A+B+C+D) & & \\
\hline
\end{tabular}

\subsubsection{Hasil Pemanfaatan Recycle air}

Hasil Recycling air dapat dilihat di neraca air, dimana rata-rata $71 \%$ Limbah dimanfaatkan kembali untuk Make-up water cooling Tower dan siram tanaman

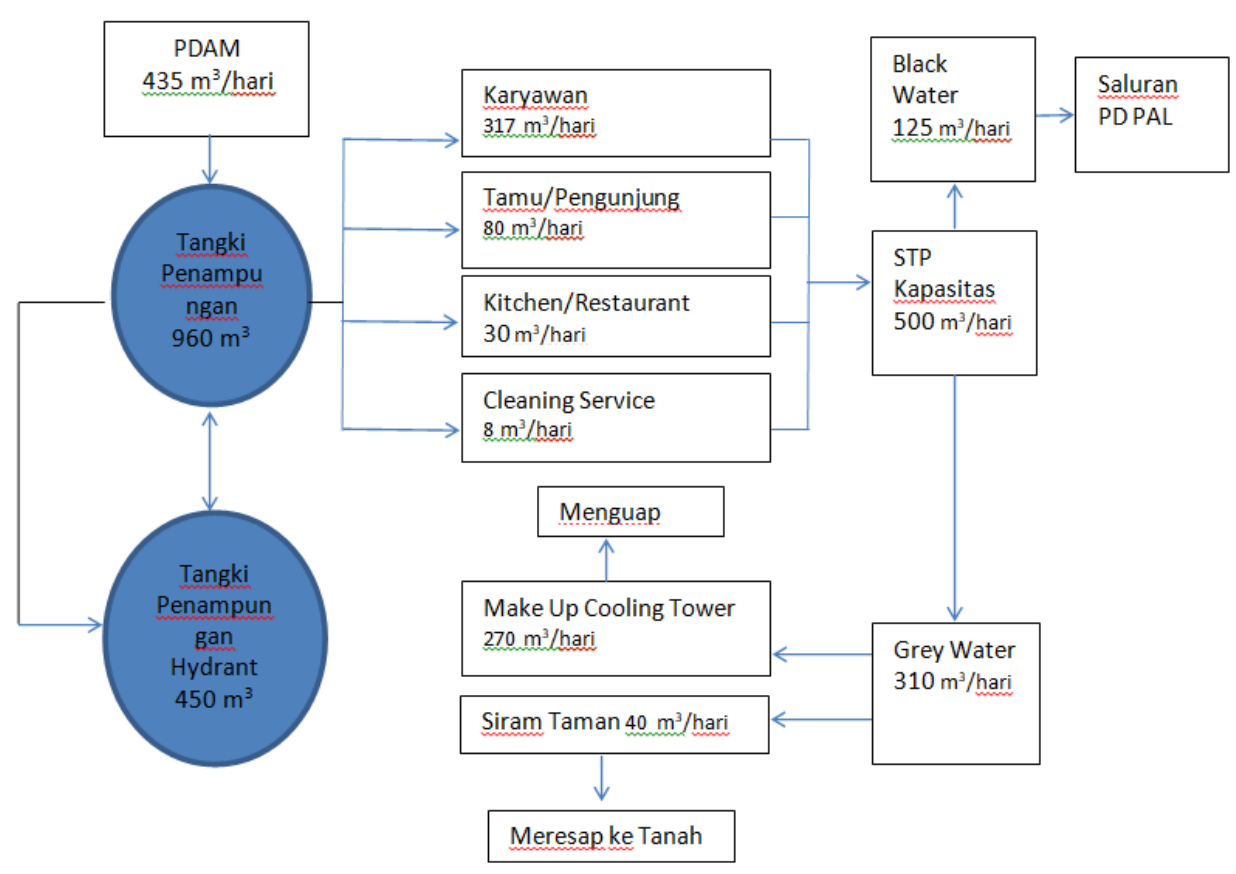

Gambar 4. Neraca Penggunaan Air Gedung

\subsection{Pembayaran Listrik PLN setelah Retrofit}

Data Pembayaran listrik bisa diketahui dari setelah selesainya retrofit yaitu mulai tahun 2017 yang bisa dilihat ditabel 7 dibawah dantabel 8 untuk tahun 2018, dimana pembayaran semakin 

Terbangun di Gedung Sampoerna Strategic Square Jakarta

turun dikarenakan selain penggantian chiller juga ada penggantian lampu konvensional dengan lampu hemat energi (LED), untuk perhitungan ROI kami menggunakan data dari tahun 2018.

Tabel 7. Perbayaran tagihan PLN tahun 2017, rata-rata perbulan Rp 2.429.646.222,25

\begin{tabular}{|l|c|r|r|r|r|}
\hline \multirow{2}{*}{ Bulan } & \multirow{2}{*}{ Tahun } & \multicolumn{2}{c|}{ PLN } & \multirow{2}{*}{ Total } & \multirow{2}{*}{ Rupiah } \\
\cline { 3 - 4 } & & LWBP & WBP & & \\
\hline Januari & 2017 & $1,862,240.00$ & $285,480.00$ & $2,147,720.00$ & $2,435,420,435.00$ \\
\hline Februari & 2017 & $1,689,240.00$ & $259,680.00$ & $1,948,920.00$ & $2,204,819,346.00$ \\
\hline Maret & 2017 & $1,960,560.00$ & $294,840.00$ & $2,255,400.00$ & $2,548,529,930.00$ \\
\hline April & 2017 & $1,759,200.00$ & $271,800.00$ & $2,031,000.00$ & $2,298,304,042.00$ \\
\hline Mei & 2017 & $1,994,880.00$ & $291,840.00$ & $2,286,720.00$ & $2,580,158,176.00$ \\
\hline Juni & 2017 & $1,701,600.00$ & $262,440.00$ & $1,964,040.00$ & $2,222,319,885.00$ \\
\hline Juli & 2017 & $1,986,120.00$ & $309,360.00$ & $2,295,480.00$ & $2,598,740,566.00$ \\
\hline Agustus & 2017 & $1,951,440.00$ & $291,120.00$ & $2,242,560.00$ & $2,532,938,539.00$ \\
\hline September & 2017 & $1,822,800.00$ & $288,360.00$ & $2,111,160.00$ & $2,392,106,931.00$ \\
\hline Oktober & 2017 & $1,962,720.00$ & $286,920.00$ & $2,249,640.00$ & $2,538,220,521.00$ \\
\hline November & 2017 & $1,899,720.00$ & $287,640.00$ & $2,187,360.00$ & $2,472,545,772.00$ \\
\hline Desember & 2017 & $1,773,000.00$ & $283,560.00$ & $2,056,560.00$ & $2,331,650,524.00$ \\
\hline \multicolumn{2}{|c|}{ Total } & $22,363,520.00$ & $3,413,040.00$ & $25,776,560.00$ & $29,155,754,667.00$ \\
\hline \multicolumn{2}{|c|}{ Rata-rata } & $1,863,626.67$ & $284,420.00$ & $2,148,046.67$ & $2,429,646,222.25$ \\
\hline
\end{tabular}

Data Pembayaran Listrik menggunakan data Tagihan Listrik PLN pada tahun 2018

Tabel 8. Perbayaran Tagihan PLN tahun 2018, Rata-Rata Perbulan Rp 2.354.609.724,57

\begin{tabular}{|l|r|r|r|r|r|}
\hline \multirow{2}{*}{ Bulan } & \multirow{2}{*}{ Tahun } & \multicolumn{2}{c|}{ PLN } & \multirow{2}{*}{ Total } & \multirow{2}{*}{ Rupiah } \\
\cline { 3 - 4 } & & \multicolumn{1}{c|}{ LWBP } & \multicolumn{1}{c|}{ WBP } & \\
\hline Januari & 2018 & $1.932 .360,00$ & $283.200,00$ & $2.215 .560,00$ & $2.500 .101 .165,00$ \\
\hline Februari & 2018 & $1.688 .400,00$ & $252.840,00$ & $1.941 .240,00$ & $2.193 .040 .256,00$ \\
\hline Maret & 2018 & $1.878 .120,00$ & $287.520,00$ & $2.165 .640,00$ & $2.449 .439 .060,00$ \\
\hline April & 2018 & $1.887 .960,00$ & $286.200,00$ & $2.174 .160,00$ & $2.457 .775 .681,00$ \\
\hline Mei & 2018 & $1.839 .600,00$ & $285.480,00$ & $2.125 .080,00$ & $2.405 .337 .702,00$ \\
\hline Juni & 2018 & $1.572 .960,00$ & $236.880,00$ & $1.809 .840,00$ & $2.045 .208 .432,00$ \\
\hline Juli & 2018 & $1.878 .720,00$ & $275.760,00$ & $2.154 .480,00$ & $2.431 .365 .776,00$ \\
\hline Agustus & 2018 & $1.840 .080,00$ & $281.160,00$ & $2.121 .240,00$ & $2.398 .973 .869,00$ \\
\hline September & 2018 & $1.785 .840,00$ & $277.320,00$ & $2.063 .160,00$ & $2.335 .335 .546,00$ \\
\hline October & 2018 & $1.948 .680,00$ & $278.520,00$ & $2.227 .200,00$ & $2.509 .959 .105,00$ \\
\hline November & 2018 & $1.818 .480,00$ & $270.960,00$ & $2.089 .440,00$ & $2.359 .836 .300,00$ \\
\hline Desember & 2018 & $1.773 .240,00$ & $265.080,00$ & $2.038 .320,00$ & $2.302 .498 .172,00$ \\
\hline \multicolumn{2}{|c|}{ Total } & $12.678 .120,00$ & $1.907 .880,00$ & $14.586 .000,00$ & $16.482 .268 .072,00$ \\
\hline \multicolumn{2}{|c|}{ Rata-rata } & $1.811 .160,00$ & $272.554,29$ & $2.083 .714,29$ & $2.354 .609 .724,57$ \\
\hline
\end{tabular}

Perbandingan Pembayaran Listrik sebelum dan sesudah Retrofit bisa kita lihat dari tabel 3 dan tabel 8, bisa diketahui bahwa selisih pembayaran listrik $=R p 2,832,542,581-R p$ 2.354.609.724,57 = Rp 477.932.856,43 / bulan

Dari Tabel 4 diketahui bahwa biaya retrofit adalah Rp 21.627.000.000,- 
Perkiraan Waktu kembalinya modal / Return of Investment $=($ Rp 21.627.000.000 / Rp 477.932.856,43) $=45,25$ bulan atau 3.77 Tahun

\subsection{Rating Greenship}

Setelah melakukan Retrofit maka Rating Greenship bisa meingkat sehingga mendapatkan nilai Platinium dengan 87 Point.
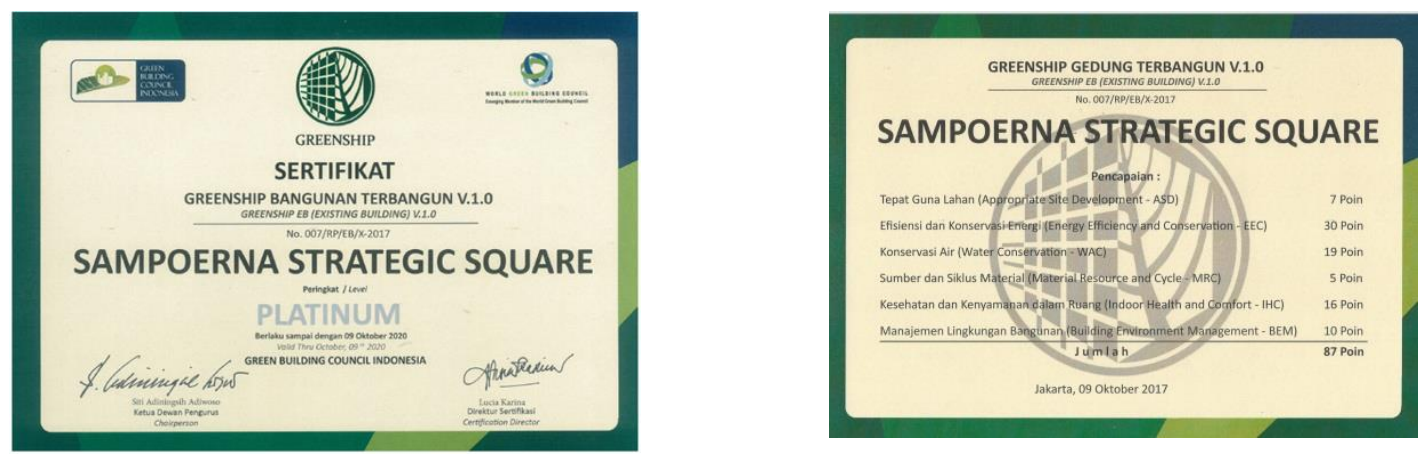

Gambar 5. Penghargaan dan Nilai yang Didapatkan Setelah Melakukan Retrofit.

\section{KESIMPULAN DAN SARAN}

Konsep Bangunan hijau / Green Building yang sedang menjadi tren secara global apabila diterapkan maka bukan saja akan memperkuat brand image dari bangunan itu sendiri tetapi juga bisa menghemat biaya operasional pengelolaan gedung, dalam studi kasus gedung sampoerna strategic square setelah melakukan pekerjaan retrofit sistem VAC dengan mengganti chiller, Recycle air buangan, penggantian dengan lampu Hemat Energi dan juga sosialisasi kepada seluruh karyawan dan penyewa, maka didapatkan penghematan dari pembayaran tagihan listrik saja sebesar Rp 477.932.856,43 / bulan (18\%) dan secara kasar akan kembali modal selama 3,77 Tahun.

Bangunan bertingkat tinggi masih mempunyai banyak potensi untuk dilakukan penelitian lebih lanjut dengan pemasangan pembangkit energi terbarukan misalnya pemasangan pembangkit listrik tenaga surya (panel surya) [7]dengan memanfaatkan atap atau fasad gedung dan juga memanfaatkan potensi gravitasi dari sistem air bersih dan sistem VAC.

\section{REFERENSI}

1. https://new.usgbc.org/ diakses 06 Mei 2019, jam 08.30 WIB

2. Shawn Roy, Prcscott C. Ensign dan Tom Brzustowski, 2016, An assessment of LEED certification's impact on net rental rates for commercial office space in Toronto, Ontario, Portland International Conference on Management of Engineering and 
Technology (PICMET), Honolulu, HI USA, 4-8 Sept. 2016, Date Added to IEEE Xplore: 05 January 2017

3. https://www.bca.gov.sg/greenmark/green_mark_buildings.html, diakses 06 Mei 2019, jam 09.20 WIB

4. http://gbcindonesia.org/, diakses 06 Mei 2019, jam 09.40 WIB

5. Peraturan Gubernur DKI Jakarta No.38 tahun 2012 Tentang Bangunan Gedung Hijau

6. SNI No. 6197-2011, Konservasi energi pada Sistem Pencahayaan, 2011

7. Pamungkas dany, Manisa Pipattanasomporn, Saifur Rahman, Nanang Hariyanto, Suwarno, 2018, ICUE 2018 on Green Energy for Sustainable Development Thavorn Palm Beach Resort Karon, Phuket, Thailand. 24 - 26 October 2018 